\title{
Generation of Calibration Charts for Horizontal Petroleum Storage Tanks Using Microsoft Excel
}

\author{
O. O. Agboola*, P. P. Ikubanni, R. A. Ibikunle, A. A. Adediran and B. T. Ogunsemi \\ Department of Mechanical Engineering, Landmark University, Omu-Aran, Kwara State, Nigeria
}

Received: 23 August 2016 / Accepted: 10 July 2017

(C) Metrology Society of India 2017

\begin{abstract}
Petroleum and petroleum products are expensive commodities due to their global demand as a major source of energy. As a result of its expensiveness, there is need for proper inventory to know what is going in and coming out of the storage tanks. Proper inventory is achieved by accurate measurement through the generation of a calibration chart for every storage tank. Calibration chart (tank table) gives the needed information about the level (height) and the corresponding volume of the petroleum product in the storage tank. Geometrical method (dry calibration) is the most widely used method of computing tank table using the field data such as circumference, shell or plate thickness, length of barrel and lap/butt strap while taking the necessary correction factors into consideration. Microsoft Excel is a powerful tool in Microsoft (MS) office package used for computation and programming through the use of visual basic for application. In this study, MS Excel was used to generate two different charts which were compared with the charts generated from customized specialized calibration software from Société Générale de Surveillance (SGS software) and the results were found to be within the statistical controlled limit.
\end{abstract}

Keywords: Calibration; Chart; Storage tanks; Tank table; Microsoft Excel

\section{Introduction}

In the petroleum industry, crude oil and its refined products exist generally in liquid or gaseous form. This bulk fluid of crude oil and its products require accurate measurement. Such accuracy eliminates disputes about the receipt of refined product or crude oil into terminal storage and on delivery, while promptly alerts operators to unnecessary product losses [1].

Storage tanks and barge tanks can generally be calibrated either by liquid calibration approach or geometric calibration [2]. Liquid method of calibration involves the determination of volume at the incremental heights of a tank by transferring a known quantity of liquid to a vessel or withdrawn from a vessel [3].

Geometrical method of tank calibration (popularly known as dry calibration) is applied to both horizontal and vertical storage tanks [4]. It is a process of gathering accurate measurements of the tank dimensions in order to use mathematical approach to determine its capacity [5].

*Corresponding author, E-mail: omegawole@gmail.com
Various approaches are being used in geometrical method of calibration. The most modernized and technically-based among them is 3D Laser scanning method as described by Knyva et al. [6]. Dou et al. [7] proposed a model for determining the tank's position in the generation of tank capacity table and the study focused more on vertical storage tanks.

Generally, horizontal storage tanks can be classified as surface horizontal tanks or underground horizontal tanks. This can further be sub-divided into flat-ended tank, elliptical-ended tank, conical, spherical and hemispherical tanks. According to Dan [8], the commonly encountered tank shapes are flat, elliptical, spherical and hemispherical. Mathematical equations have been developed for all these commonly encountered shapes through which the volume at various heights can be computed. Sun [9] asserted that determination of tank capacity is not as simple as it may appear because of some other factors which are different from the common correction factors such as temperature, shell thickness, heads/ends. In a bid to accurately determine the capacity of horizontal storage tanks, the volume of the straight cylindrical section is first determined before adding it to the volume of the ends. This is easily done for straight/perfectly horizontal tanks. However, it poses a 
very difficult task for inclined or tilted tanks because there is need to take into consideration the effect of tilt [10]. Tilt is not always a desirable condition in the installation of horizontal tanks but it may be intentionally done in some rare conditions which include enhancing free flow from one section to the other. Correction for the effect of tilt and its optimization was given by Wei et al. [11] where a model of oil volume marking for a tilted oil tank was validated.

Calibration of a horizontal storage tank should be done once in every five (5) years [12]. Tank capacity table, which is the output of tank calibration process, is a set of data relating the filled volume of storage tank to the gauge height/ level. MS-Excel has been used over the years for mathematical calculation instead of manual calculations [13]. When a correct program is written on a spreadsheet, the output would definitely be right. Sanjid and Chaudhary [14] designed a software for the calibration of angle block and validated it with the results obtained from MS-Excel calculation. Validation could be done by comparing already existing method(s) with the new proposed method. Chunhui and Johnson [15] researched into the bilateral comparison between NIM's and NIST's gas flow standards and found that all the data are in compliance with ISO 9300 empirical equation within its $0.3 \%$ expanded uncertainty limit.

Having searched extensively in Nigeria by meeting with the renowned calibration companies to know if there are commercialized softwares for Tank calibration, it was discovered that none ever existed up till date. However, most companies combine various standards such as API, IP and ISO together to do manual computations. In order to reduce this rigorous task, the use of API 2551 was adopted in this work in addition to the exact mathematical findings of Dan [8] to generate calibration charts using MS Excel programme. This research aims at generating calibration charts for horizontal cylindrical storage tanks using simple Microsoft Excel programme. The programme interface is user-friendly. This makes the task of generating calibration charts simple.

\section{Materials and Methods}

Geometrical calibration involves different linear measurements such as knowing the circumference, shell plate thickness, tilt/slope etc. Equipment such as strapping tape is used to obtain the circumference of the tank. Ultrasonic Thickness Gauging (UTG) model TG110L machine was used for determining the shell thickness while leveling instrument was used to determine the degree of tilt.

\subsection{Field Measurement}

The three (3) basic measurements made on site were the circumference, shell plate thickness, tilt/slope (if any), and shell temperature. Though, there are two possible methods of physical measurements which are external and internal measurement, however; the scope of this paper is limited to external measurement because most of the storage tanks abide by external measurement except the insulated tanks where internal measurements are adopted.

\subsection{Circumferential Measurement}

Horizontal tanks consist of two heads commonly called ends. Amid the two heads is a cylindrical section called barrel. It is important to note that for a flat-ended tank, there is only barrel but no head.

Circumferences were measured at 20,50 and $80 \%$ of the barrel length by winding a strapping tape round the shell at these various sections. The strapping tape was firmly held under tension using "little John grip". The circumferences obtained for two different Tank A and Tank A1 are as shown in Tables 1 and 2.

\subsection{Shell Plate Thickness}

The thickness of every section of the barrel as well as the end thicknesses was taken using UTG for spot scanning. The scanning was simultaneously done on the tank barrel. The field data obtained was shown in the Tables 3 and 4, respectively for Tanks A and A1.

\subsection{Slope Measurement}

No slope was found in Tank A because the value obtained as both assumed shallow end and deep end were the same. However, for Tank A1, negligible tilt value was observed. The observed value obtained in shallow end was $765 \mathrm{~mm}$ while $759 \mathrm{~mm}$ was obtained at the deep end.

\subsection{Temperature}

Master tape was certified at $23{ }^{\circ} \mathrm{C}$ but the field measurement was carried out at about $29-33{ }^{\circ} \mathrm{C}$ for both Tanks A and $\mathrm{A} 1$.

\subsection{End Measurement}

By visual inspection, Tank A has a conical shaped end with average cone radius of $78 \mathrm{~mm}$ whereas Tank A1 was an elliptical ended tank with a dish radius of $52 \mathrm{~mm}$.

Table 1 Circumferential measurement of Tanks A

\begin{tabular}{llll}
\hline & $20 \%$ & $50 \%$ & $80 \%$ \\
\hline Circumference (mm) & 9464 & 9463 & 9464 \\
\hline
\end{tabular}


Table 2 Circumferential measurement of Tanks A1

\begin{tabular}{llll}
\hline & $20 \%$ & $50 \%$ & $80 \%$ \\
\hline Circumference (mm) & 9476 & 9477 & 9479 \\
\hline
\end{tabular}

Table 3 Average thickness and Length of barrel for tank A

\begin{tabular}{ll}
\hline Average thickness (mm) & 6.0 \\
Length of barrel (mm) & 6000
\end{tabular}

Table 4 Average thickness and Length of barrel for tank A1

Average thickness (mm) 8.0

Length of barrel (mm) $\quad 7500$

\subsection{Computation of Tank Capacity Table}

Volumetric quantity as a function of height (level) can be calculated from the exact mathematical findings of Dan [8]. Both ends of the tank must be identical and assumed to have the same dimensions for the equations to be valid. If one end is elliptical, the other must be elliptical with the same dimensions. However, the equations can be combined to deal with volumetric calculations of horizontal tanks with ends of different shapes.

In this computation, the two ends were treated together as a single section while the cylindrical barrel was also treated separately. The two sections were combined together to give the required volume of horizontal cylindrical tanks.

Generation of any tank capacity table starts from skeleton chart and consideration of different correction factors. Some of these correction factors are:

1. Effect of temperature.

2. Effect of Shell plate thickness.

3. Effect of tilt.

4. Effect of butt strap (usually applicable to vertical storage tanks).

\subsection{Correction for the Effect of Temperature}

The petroleum industry uses $60^{\circ} \mathrm{F}$ ( or $15^{\circ} \mathrm{C}$ ) as standard temperature for petroleum products. The master tape could be calibrated to this temperature using the equation:

Correction factor $=1+\left[\left(T_{\mathrm{s}}-T_{\mathrm{c}}\right) \times C\right]$
$T_{c}$ is the calibration temperature of master tape, $T_{s}$ is the reference temperature, $C$ coefficient of expansion for mild steel $0.00000645 \mathrm{ft} / \mathrm{ft} /$ Degree Fahrenheit.

The average circumference of each course shell is then multiplied by the temperature correction factor to obtain the corrected circumference for each course.

\subsection{Correction for the Effect of Shell Plate Thickness}

Required internal circumference $c=c_{\mathrm{o}}-2 \pi t$

where $c_{\mathrm{o}}$ is the corrected outer circumference, $t$ average thickness of each shell plate.

\subsection{Correction for the Effect of Tilt/Slope}

Two corrections are usually made for the effects of tilt. These include:

$T_{1}=y D\left(L_{\mathrm{R}}^{2}-L_{\mathrm{L}}^{2}\right) \times \frac{\sin \alpha}{2}$

$T_{2}=y^{2} \times\left(L_{\mathrm{R}}^{3}+L_{\mathrm{L}}^{2}\right) \times \frac{\cot \alpha}{3}$

$\mathrm{L}_{\mathrm{R}}$ length of high end, $\mathrm{L}_{\mathrm{L}}$ length of low end, $D$ diameter of the cylinder, $y$ slope

\subsection{Correction for the Effect of Butt Strap}

This correction is not normally applied to horizontal tanks except when the number of weld per ring exceeds 5 . However, this is usually taken into consideration in the calibration of vertical storage tanks [10]

Deduction $=\frac{2 \mathrm{NtW}}{d}+\frac{8 \mathrm{Nt}}{3} \sqrt{t / d}$

where $N$ is the number of butt straps or projections per ring, $t$ is the amount of rise (thickness of straps or projections), $W$ is the width of straps or projections, in inches, $d$ is the nominal diameter of tank in inches

\subsection{Overall Tank Capacity Table}

\subsubsection{Volume of Barrel}

The barrel is cylindrical in shape, so its mathematical derivate is the same irrespective of the attached ends. Exact

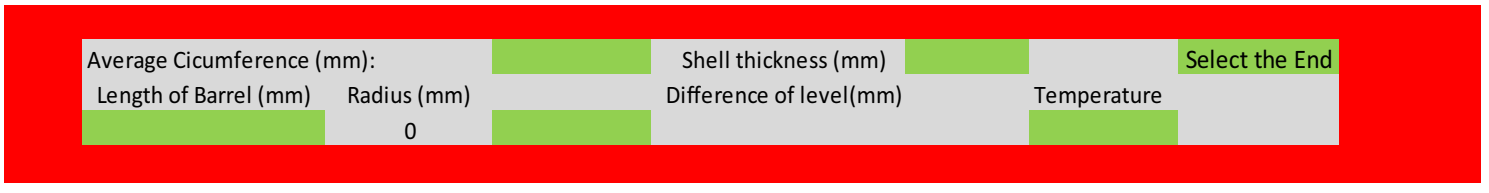

Fig. 1 Interface for MS-Excel programme for horizontal tank calibration 
Table 5 Chart for Tank A

\begin{tabular}{|c|c|c|c|}
\hline Level (mm) & $\begin{array}{l}\text { Excel prog. } \\
\text { Volume (L) }\end{array}$ & $\begin{array}{l}\text { SGS software } \\
\text { Volume (L) }\end{array}$ & $\%$ Deviation \\
\hline 0 & 0 & 0 & 0.00 \\
\hline 10 & 14 & 14 & 0.00 \\
\hline 20 & 39 & 39 & 0.01 \\
\hline 30 & 72 & 72 & 0.01 \\
\hline 40 & 110 & 110 & 0.01 \\
\hline 50 & 154 & 154 & 0.01 \\
\hline 60 & 203 & 203 & 0.01 \\
\hline 70 & 255 & 255 & 0.01 \\
\hline 80 & 311 & 311 & 0.01 \\
\hline 90 & 371 & 371 & 0.01 \\
\hline 100 & 434 & 434 & 0.02 \\
\hline 110 & 500 & 500 & 0.02 \\
\hline 120 & 570 & 570 & 0.02 \\
\hline 130 & 642 & 642 & 0.02 \\
\hline 140 & 716 & 716 & 0.02 \\
\hline 150 & 794 & 794 & 0.02 \\
\hline 160 & 873 & 874 & 0.02 \\
\hline 170 & 956 & 956 & 0.02 \\
\hline 180 & 1040 & 1040 & 0.02 \\
\hline 190 & 1127 & 1127 & 0.02 \\
\hline 200 & 1216 & 1216 & 0.02 \\
\hline 210 & 1307 & 1307 & 0.02 \\
\hline 220 & 1400 & 1400 & 0.02 \\
\hline 230 & 1495 & 1495 & 0.02 \\
\hline 240 & 1592 & 1592 & 0.02 \\
\hline 250 & 1691 & 1691 & 0.02 \\
\hline 260 & 1792 & 1792 & 0.02 \\
\hline 270 & 1894 & 1894 & 0.02 \\
\hline 280 & 1998 & 1999 & 0.02 \\
\hline 290 & 2104 & 2105 & 0.02 \\
\hline 300 & 2212 & 2212 & 0.02 \\
\hline 310 & 2321 & 2321 & 0.02 \\
\hline 320 & 2432 & 2432 & 0.02 \\
\hline 330 & 2544 & 2544 & 0.02 \\
\hline 340 & 2658 & 2658 & 0.02 \\
\hline 350 & 2773 & 2774 & 0.02 \\
\hline 2660 & 40,122 & 40,143 & 0.05 \\
\hline 2670 & 40,236 & 40,257 & 0.05 \\
\hline 2680 & 40,348 & 40,369 & 0.05 \\
\hline 2690 & 40,459 & 40,480 & 0.05 \\
\hline 2700 & 40,568 & 40,590 & 0.05 \\
\hline 2710 & 40,675 & 40,697 & 0.05 \\
\hline 2720 & 40,781 & 40,803 & 0.05 \\
\hline 2730 & 40,886 & 40,908 & 0.05 \\
\hline 2740 & 40,988 & 41,010 & 0.05 \\
\hline 2750 & 41,089 & 41,111 & 0.06 \\
\hline 2760 & 41,188 & 41,210 & 0.06 \\
\hline 2770 & 41,285 & 41,308 & 0.06 \\
\hline
\end{tabular}

Table 5 continued

\begin{tabular}{|c|c|c|c|}
\hline Level (mm) & $\begin{array}{l}\text { Excel prog. } \\
\text { Volume (L) }\end{array}$ & $\begin{array}{l}\text { SGS software } \\
\text { Volume (L) }\end{array}$ & $\%$ Deviation \\
\hline 2780 & 41,380 & 41,403 & 0.06 \\
\hline 2790 & 41,473 & 41,496 & 0.06 \\
\hline 2800 & 41,564 & 41,587 & 0.06 \\
\hline 2810 & 41,653 & 41,677 & 0.06 \\
\hline 2820 & 41,740 & 41,764 & 0.06 \\
\hline 2830 & 41,824 & 41,848 & 0.06 \\
\hline 2840 & 41,906 & 41,931 & 0.06 \\
\hline 2850 & 41,986 & 42,011 & 0.06 \\
\hline 2860 & 42,063 & 42,088 & 0.06 \\
\hline 2870 & 42,138 & 42,163 & 0.06 \\
\hline 2880 & 42,210 & 42,236 & 0.06 \\
\hline 2890 & 42,279 & 42,305 & 0.06 \\
\hline 2900 & 42,346 & 42,372 & 0.06 \\
\hline 2910 & 42,409 & 42,435 & 0.06 \\
\hline 2920 & 42,469 & 42,495 & 0.06 \\
\hline 2930 & 42,525 & 42,552 & 0.06 \\
\hline 2940 & 42,577 & 42,605 & 0.06 \\
\hline 2950 & 42,626 & 42,653 & 0.06 \\
\hline 2960 & 42,669 & 42,697 & 0.07 \\
\hline 2970 & 42,708 & 42,736 & 0.07 \\
\hline 2980 & 42,741 & 42,770 & 0.07 \\
\hline 2990 & 42,766 & 42,795 & 0.07 \\
\hline 3000 & 42,780 & 42,810 & 0.07 \\
\hline
\end{tabular}

All values under volume for both Excel programme and SGS software are rounded off to the nearest whole number. However, the full values were used for the computation of $\%$ deviation $\left\{\left(\frac{\text { SGS volume-Excel prog volume }}{\text { SGS volume }}\right) \times 100\right\}$ before rounding up to 2 decimal places

mathematical equation of horizontal cylinder with respect to its height is given as

$V_{\text {cy }}=$ Cross - sectional area, $A \times$ length, $L$

$$
\begin{aligned}
V_{\text {cy }}= & L \times\left[R^{2} \cos ^{-1}\left(\frac{R-h}{R}\right)-\left((R-h) \sqrt{2 R h-h^{2}}\right)\right] \\
& +\left(T_{1}+T_{2}\right)
\end{aligned}
$$

where $R$ radius of the cylindrical barrel $(\mathrm{mm}), h$ height (level) in mm measured from the dip point, $L$ length of barrel in (mm), $T_{1}$ and $T_{2}$ are the corrections for the effect of tilt as shown in Eqs. 3 and 4.

Equations (3-6) above is converted to Litres (L) by multiplying with $10^{-6}$.

\subsubsection{Volume of the Ends}

As earlier stated, the two heads were treated together as one. The three heads commonly encountered are discussed below. 
Table 6 Chart for Tank A1

\begin{tabular}{|c|c|c|c|}
\hline Level (mm) & $\begin{array}{l}\text { Excel prog. } \\
\text { Volume (L) }\end{array}$ & $\begin{array}{l}\text { SGS software } \\
\text { Volume (L) }\end{array}$ & $\%$ Deviation \\
\hline 0 & 0 & 0 & 0.00 \\
\hline 10 & 17 & 17 & -0.02 \\
\hline 20 & 49 & 49 & 0.02 \\
\hline 30 & 90 & 90 & 0.01 \\
\hline 40 & 138 & 138 & 0.01 \\
\hline 50 & 193 & 193 & 0.02 \\
\hline 60 & 254 & 254 & 0.02 \\
\hline 70 & 319 & 319 & 0.02 \\
\hline 80 & 390 & 390 & 0.02 \\
\hline 90 & 465 & 465 & 0.02 \\
\hline 100 & 544 & 544 & 0.02 \\
\hline 110 & 627 & 627 & 0.02 \\
\hline 120 & 714 & 714 & 0.02 \\
\hline 130 & 804 & 804 & 0.02 \\
\hline 140 & 898 & 898 & 0.02 \\
\hline 150 & 995 & 995 & 0.02 \\
\hline 160 & 1095 & 1095 & 0.02 \\
\hline 170 & 1198 & 1198 & 0.02 \\
\hline 180 & 1304 & 1304 & 0.02 \\
\hline 190 & 1413 & 1413 & 0.02 \\
\hline 200 & 1524 & 1524 & 0.02 \\
\hline 210 & 1638 & 1639 & 0.02 \\
\hline 220 & 1755 & 1755 & 0.02 \\
\hline 230 & 1874 & 1875 & 0.03 \\
\hline 240 & 1996 & 1996 & 0.03 \\
\hline 250 & 2120 & 2120 & 0.03 \\
\hline 260 & 2246 & 2247 & 0.03 \\
\hline 270 & 2374 & 2375 & 0.03 \\
\hline 280 & 2505 & 2506 & 0.03 \\
\hline 290 & 2638 & 2639 & 0.03 \\
\hline 300 & 2773 & 2773 & 0.03 \\
\hline 310 & 2910 & 2910 & 0.03 \\
\hline 320 & 3048 & 3049 & 0.03 \\
\hline 330 & 3189 & 3190 & 0.03 \\
\hline 340 & 3332 & 3333 & 0.03 \\
\hline 350 & 3477 & 3478 & 0.03 \\
\hline 2660 & 50,169 & 50,214 & 0.09 \\
\hline 2670 & 50,312 & 50,357 & 0.09 \\
\hline 2680 & 50,453 & 50,498 & 0.09 \\
\hline 2690 & 50,592 & 50,637 & 0.09 \\
\hline 2700 & 50,728 & 50,775 & 0.09 \\
\hline 2710 & 50,863 & 50,910 & 0.09 \\
\hline 2720 & 50,996 & 51,043 & 0.09 \\
\hline 2730 & 51,127 & 51,174 & 0.09 \\
\hline 2740 & 51,255 & 51,303 & 0.09 \\
\hline 2750 & 51,381 & 51,429 & 0.09 \\
\hline 2760 & 51,505 & 51,554 & 0.09 \\
\hline 2770 & 51,627 & 51,676 & 0.09 \\
\hline
\end{tabular}

Table 6 continued

\begin{tabular}{|c|c|c|c|}
\hline Level (mm) & $\begin{array}{l}\text { Excel prog. } \\
\text { Volume (L) }\end{array}$ & $\begin{array}{l}\text { SGS software } \\
\text { Volume (L) }\end{array}$ & $\%$ Deviation \\
\hline 2780 & 51,746 & 51,795 & 0.10 \\
\hline 2790 & 51,863 & 51,912 & 0.10 \\
\hline 2800 & 51,977 & 52,027 & 0.10 \\
\hline 2810 & 52,088 & 52,139 & 0.10 \\
\hline 2820 & 52,197 & 52,248 & 0.10 \\
\hline 2830 & 52,303 & 52,354 & 0.10 \\
\hline 2840 & 52,406 & 52,458 & 0.10 \\
\hline 2850 & 52,506 & 52,558 & 0.10 \\
\hline 2860 & 52,603 & 52,656 & 0.10 \\
\hline 2870 & 52,697 & 52,750 & 0.10 \\
\hline 2880 & 52,787 & 52,841 & 0.10 \\
\hline 2890 & 52,874 & 52,928 & 0.10 \\
\hline 2900 & 52,957 & 53,011 & 0.10 \\
\hline 2910 & 53,036 & 53,091 & 0.10 \\
\hline 2920 & 53,110 & 53,166 & 0.10 \\
\hline 2930 & 53,181 & 53,237 & 0.11 \\
\hline 2940 & 53,247 & 53,303 & 0.11 \\
\hline 2950 & 53,307 & 53,364 & 0.11 \\
\hline 2960 & 53,362 & 53,420 & 0.11 \\
\hline 2970 & 53,410 & 53,468 & 0.11 \\
\hline 2980 & 53,451 & 53,510 & 0.11 \\
\hline 2990 & 53,482 & 53,542 & 0.11 \\
\hline 3000 & 53,500 & 53,561 & 0.11 \\
\hline
\end{tabular}

All values under volume for both Excel programme and SGS software are rounded off to the nearest whole number. However, the full values were used for the computation of $\%$ deviation $\left\{\left(\frac{\text { SGS volume-Excel prog volume }}{\text { SGS volume }}\right) \times 100\right\}$ before rounding up to 2 decimal places

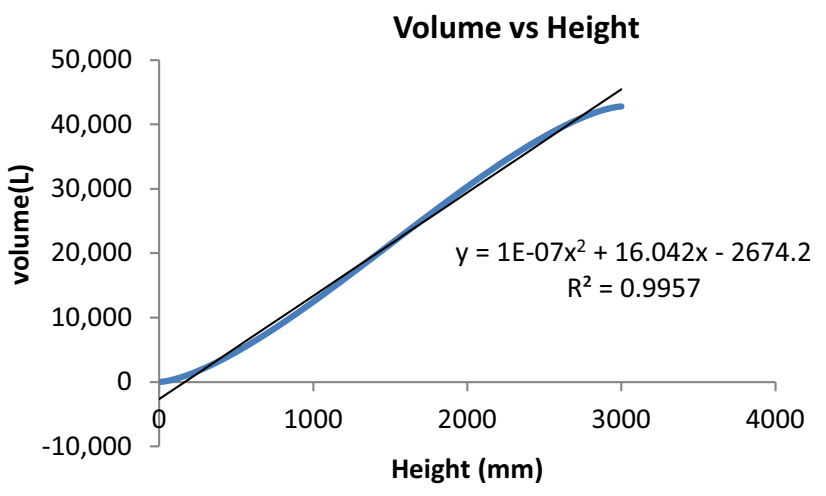

Fig. 2 Volume against height for Tank A using Excel programme

\subsubsection{Conical Ends}

A conical-ended tank has a cone rise $c_{r}$ measured from the centre of the cylindrical section to where the cone ends. Conical end is sub-divided into three distinct sections: 


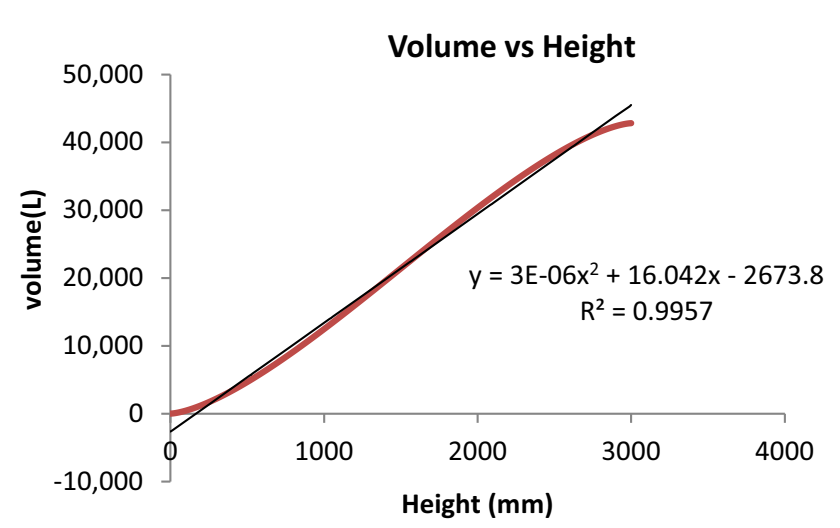

Fig. 3 Volume against height for Tank A using SGS

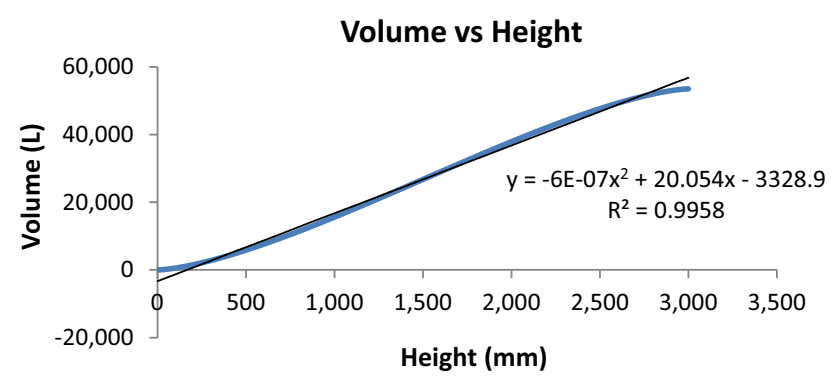

Fig. 4 Volume against height for Tank A1 using Excel programme

1. When the measured height $h$ is less greater than zero but less than the radius of the cylindrical barrel $R$ (i.e. $0 \leq h<R)$.

2. When measured height $h$ is equal to the radius of the cylindrical barrel $R$ (i.e. $h=R$ ).

3. When radius of the cylindrical barrel $R$ is less than the measured height $h$ but $h$ too less than or equal to $2 \mathrm{R}$ (i.e. $R<h \leq 2 R$ ).

The volumes of the conical end at these three sections are given in mathematical form as:

For $0 \leq h<R$,

Conical end volume $V_{\mathrm{cn}}=\frac{2 c_{\mathrm{r}} R^{2} K}{3}$

For $h=R$,

Conical end volume, $V_{\mathrm{cn}}=\frac{2 c_{\mathrm{r}} R^{2}}{3} \times \frac{\pi}{2}$

For $R<h \leq 2 R$,

Conical end volume, $V_{\mathrm{cn}}=\frac{2 c_{\mathrm{r}} R^{2}}{3} \times(\pi-K)$

But

$\mathrm{K}=\cos ^{-1} M+M^{3} \cosh ^{-1} \frac{1}{M}-2 M \sqrt{1-M^{2}}$
$\mathrm{M}=\left|\frac{R-h}{R}\right|$

$\mathrm{c}_{\mathrm{r}}$ cone rise $(\mathrm{mm}), R$ radius of the cylindrical section, $h$ measured height/level $(\mathrm{mm})$ and $V_{\mathrm{cn}}$ conical ended volume [8].

\subsubsection{Elliptical Ends}

For elliptical ended tanks, ellipsoidal radius $\mathrm{e}_{\mathrm{r}}$ is measured from the centre of the cylindrical barrel

Elliptical volume, $V_{\mathrm{e}}=\pi e_{\mathrm{r}} h^{2}\left(1-\frac{h}{3 R}\right)$

where $\mathrm{V}_{\mathrm{e}}$ elliptical volume, $\mathrm{e}_{\mathrm{r}}$ elliptical radius $(\mathrm{mm})$, $h$ measured height/level $(\mathrm{mm})$.

\subsubsection{Hemispherical Ends}

When two hemispherical ends combine, they give a complete sphere. Hence, the volume of hemispherical ends $V_{\mathrm{h}}$ is given as:

$V_{\mathrm{h}}=\frac{\pi h^{2}}{3}(3 R-h)$

where $V_{\mathrm{h}}$ hemispherical heads volume, $R$ radius of the cylindrical section $(\mathrm{mm}), h$ measured height/level $(\mathrm{mm})$

\subsection{MS Excel Programme Interface}

The interface where the inputs are supplied is shown in Fig. 1.

\section{Results}

Information from Tanks A and A1 were fed into both the MS-Excel programme and SGS software and the chart generated for each of the tanks are displayed in Tables 5 and 6 respectively.

\section{Discussion}

From the Tables 5 and 6 , the maximum deviation and average deviation for Tank A are 0.07 and 0.03 respectively while the maximum deviation and average deviation for tank A1 are 0.11 and 0.06 respectively. The above deviations are consistent with the provision of $0.3 \%$ variation of the indicated volume [12]. Adetokunbo [16] reported on the effectiveness of geometrical method of tank calibration where it was observed that the maximum deviation noted for chat obtained from SGS and chart from 


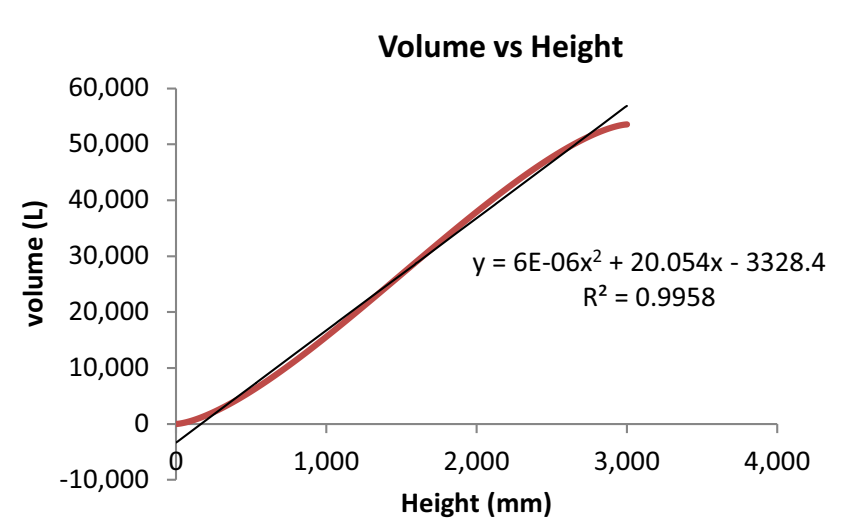

Fig. 5 Volume against Height for Tank A1 using SGS software

Wet calibration of $45,000 \mathrm{~L}$ amounts to 0.006 . The trend obtained from SGS chart was corroborated with the use of MS Excel package. As a result, there was consistency of results from both charts.

Apart from the fact that the two charts generated from MS-Excel fell within the acceptable limit of \pm 0.25 as stipulated in the manual of petroleum measurement standards (MPMS), the average time of computation using excel programme is between 180 and $240 \mathrm{~s}$ when compared with SGS software which took about an average of 540-660 s.

Also Figs. 2 and 3 which are the graph of volume versus height for Tank A for both Excel programme and SGS software have the same coefficient of determination $R^{2}=0.9957$. The same thing applies for Figs. 4 and 5 for Tank A1 which have coefficient of determination $R^{2}=0.9958$. Though, the model equations for Figs. 2 and 3 may not exactly be the same but have the same coefficient of determination $R^{2}=0.9957$ which confirms the authenticity and correctness of the developed excel programme.

\section{Conclusion}

Going by the results obtained above, it can be concluded that MS-Excel programme is a better alternative to the customized tank calibration software. Excel is a common software, readily available and easy to learn. Once the algorithm is understood, computation is easily done.
Calibrator and Calibration Companies are therefore encouraged to take the better advantage that MS Excel offers.

\section{References}

[1] E. A. Agboola, Petroleum product measurement and quality assurance, presentation at the National Seminar on Petroleum Measurement, Department of Petroleum Resources, Lagos, Nigeria (2009).

[2] V. Knyva, M. Knyva and J. Rainys, New approach to calibration of vertical fuel tank, J. Elektron. Elektrotech. 19(8) (2013).

[3] API 2555, Method for liquid calibration of tank, Measurement Coordination Department, Washington, DC (1998).

[4] J. Guan and H. Zhao, Practical methods of oil volume calibration of horizontal storage tank. Metrol. Meas. Tech. 31(3) (2004) 21-36.

[5] API MPMS 2.2F, Measurement and calibration of vertical cylindrical tank. Measurement Coordination Department, Washington, DC (2000).

[6] M. Knyva, V. Knyva, Z. Nakutis, V. Dumbrava and M. Saunoris, A concept of fuel tank calibration process automation within IoT infrastructure. MAPAN-J. Metrol. Soc. India 32(1) (2017) 7-15.

[7] J. Dou, Y. Mei, Z. Chen and L. Wang, Model of the identification of oil tank's position and the calibration of tank capacity table. Pure Appl. Math. 27(6) (2011) 829-840.

[8] J. Dan, Calculating tank volume. http://www.webcalc.com.br/ blog/Tank_Volume.PDF (May, 2015).

[9] F. J. Sun, A Discussion on some difficulties in calibration calculation of horizontal oil tank volume. J. Petrol. Prod. Appl. Res. 18(5) (2000) 20-24.

[10] T. J. Tian, Volume calculation of straight cylindrical part of tilted horizontal tanks. J. Mod. Meas. Test 5 (1999) 32-36.

[11] X. Wei, W. Xiaojing, C. Huizhe, C. Jun, Optimization model of oil-volume marking with tilted oil tank. Open J. Optim. 1 (2012) $20-24$.

[12] OIML R 71 Fixed storage tanks-general requirements. OIML (2008).

[13] X. Weiwei and W. Guodong, Design and implication of a system of measuring oil volume of underground tank. J. Linyi Norm. Univ. 29(3) (2007) 31-33.

[14] M. A. Sanjid and K. P. Chaudhary, Validation of software used for calibration of angle block at CSIR-NPL India. MAPAN-J. Metrol. Soc. India 31(1), (2016) 31-41.

[15] L. Chunhui and A. Johnson, Bilateral comparison between NIM's and NIST's gas flow standards. MAPAN-J. Metrol. Soc. India 26(3) (2011) 211-224.

[16] O. Adetokunbo, Calibration of oil storage tanks, presentation at the Department of Petroleum Resources, Portharcourt branch office, Nigeria (2012). 